\title{
Production of Haploids in Persian Walnut through Parthenogenesis Induced by Gamma-irradiated Pollen
}

\author{
Mohammad Sadat Hosseini Grouh ${ }^{1}$, Kourosh Vahdati ${ }^{2}$, and Mahmoud Lotfi \\ Department of Horticulture, College of Abouraihan, P.O. Box 33955-159, University of Tehran, \\ Tehran, Iran 3391653775 \\ Darab Hassani \\ Department of Horticulture, Seed and Plant Improvement Institute, P.O. Box 31585-4119, Karaj, \\ Iran 3183963843
}

\author{
Nejat Pirvali Biranvand \\ Agricultural, Medical \& Industrial Research School, P.O. Box 31485-498, Karaj, Iran
}

\begin{abstract}
AdDitional INDEX wORDS. chromosome, Juglans regia, flow cytometry, line, molecular markers, ploidy, SSR
ABSTRACT. We report the first successful regeneration of haploid lines in persian walnut (Juglans regia) developed by in situ parthenogenesis followed by embryo rescue. Female flowers of cultivars Hartley and Pedro and two native Iranian selections $\left(Z_{63}\right.$ and $\left.Z_{67}\right)$ were pollinated using pollen of selections $Z_{53}$ and $Z_{30}$ that had been irradiated with gamma rays at five doses $(50,150,300,600$, and $900 \mathrm{~Gy})$. Gamma-irradiated pollen induced fruit set and development of some parthenogenetic embryos. The immature embryos were excised 30 and 45 days after pollination, cultured in vitro, and then stratified for 30 days at $4{ }^{\circ} \mathrm{C}$ to overcome dormancy. Ploidy level of the resulting plantlets was determined by chromosome counting and flow cytometry. Haploid plants were obtained from 'Hartley', 'Pedro', $Z_{63}$, and $\mathrm{Z}_{67}$ after pollination using pollen irradiated at 300 and $600 \mathrm{~Gy}$. Plants obtained from pollen irradiated at 50 and $150 \mathrm{~Gy}$ were all diploid. Molecular marker analysis using four simple sequence repeat (SSR) markers also showed that all the diploid plants recovered were zygotic and no spontaneous double haploid plants were obtained in this work. Also, the haploid plantlets presented only one allele of their female parents. These profiles confirmed the parthenogenetic origin of the obtained haploid plants. The techniques used to induce haploid walnut plants by irradiated pollen were successful and could be used in breeding programs and accelerate genome analysis in this plant in which the genome size is approximately three times the size of the human genome.
\end{abstract}

Most fruit tree species are characterized by a high degree of heterozygosity, long juvenility, large size, and sometimes selfincompatibility. For these reasons, progress in breeding programs through conventional methods (i.e., generations of crossing and selection) is time-consuming and limited by available space for field experiments. Biotechnological techniques such as production of haploids offer new opportunities for genetic research in breeding programs (Höfer and Grafe, 2003). Haploids and di-haploids (DHs) are important for genetic and developmental studies as well as for plant breeding. They have potential use in mutation research, genetic analysis, transformation, and in the production of homozygous culti$\operatorname{var}(\mathrm{s})$ that can be used to produce $\mathrm{F}_{1}$ hybrids for exploitation of heterosis (Germana, 2009). DHs are also very useful for genome mapping, providing reliable information about the location of major genes and quantitative trait loci for economically important traits (Khush and Virmani, 1996). Several methods have been tested for induction of haploids, including anther and microspore culture and in situ parthenogenesis by

Received for publication 3 Nov. 2010. Accepted for publication 24 Feb. 2011. We thank the University of Tehran and Iran National Science Foundation (INSF) for financial support and the Seed and Plant Improvement Institute for providing the plant materials. Charles Leslie and Pedro Martínez Gómez are also acknowledged for kindly editing the manuscript.

${ }^{1}$ Current address: Department of Plant Production, Faculty of Agriculture, University of Jiroft, Jiroft, Iran.

${ }^{2}$ Corresponding author. E-mail: kvahdati@ut.ac.ir. irradiated pollen followed by in vitro culture of immature embryos in fruit trees (Germana, 2006).

Haploid production through in situ parthenogenesis has been reported in fruit trees species such as apple [Malus $\times$ domestica (Höfer and Lespinasse, 1996; Zhang and Lespinasse, 1991)], pear [Pyrus communis (Bouvier et al., 1993)], sweet cherry [Prunus avium (Höfer and Grafe, 2003)], kiwifruit [Actidinia deliciosa (Chalak and Legave, 1997, Pandey et al., 1990)], and clementine [Citrus reticulata (Ollitrault et al., 1996)]. In mandarin 'Fortune' (Citrus clementina $\times$ C. tangerina) and 'Ellendale' $(C$. reticulata $\times C$. sinensis $)$, haploid induction was successfully performed through in situ parthenogenesis followed by immature embryo culture (Froelicher et al., 2007). The selection of an efficient radiation dose, the optimization of the pollination method, the seed collection time, the developmental stage, the culture media, and culture conditions are all important factors affecting the success of this technique and the number of haploid embryos rescued (Germana, 2009).

The purpose of this research was to evaluate the use of gamma-irradiated pollen for production of parthenogenetic haploid plants in persian walnut. Viability of irradiated pollen, percent fruit set, parthenogenetic embryos formation, and the first production of haploid plants in walnut are reported.

\section{Materials and Methods}

Plant material. The experiments were conducted in 2008 and 2009. Cultivars Hartley and Pedro and two native selections 
$\left(\mathrm{Z}_{63}\right.$ and $\left.\mathrm{Z}_{67}\right)$ were used as female parents. As a result of frost injury, the $Z_{63}$ and $Z_{67}$ genotypes were not used in 2009 . Genotypes $Z_{53}$ and $Z_{30}$ were used as the pollen parents in the 2008 experiment but only $Z_{30}$ in 2009 . $Z_{30}$ and $Z_{53}$ were chosen as pollen parents for their protandrous bloom habit with an extended period of pollen production. Field experiments were conducted at the walnut collection of the Kamal Shahr Station, Seed and Plant Improvement Institute at Karaj in northwest Tehran Province, Iran (lat. $35^{\circ} 48^{\prime} \mathrm{N}$, long. $51^{\circ} 2^{\prime} \mathrm{E}$ ).

Pollen irRadiation and pollination. Pollen irradiation was performed in small glass tubes $(9 \times 45 \mathrm{~mm})$ using gamma rays produced from a Cobalt 60 source at doses of $0,50,150$, 300 , and 600 Gy in 2008 and 0, 300, 600, and 900 Gy in 2009. The pistillate flowers of 'Hartley', 'Pedro', $\mathrm{Z}_{63}$, and $\mathrm{Z}_{67}$ were isolated using cloth bags and the controlled crosses were performed using irradiated and control pollen of $Z_{53}$ and $Z_{30}$ applied when the angle between the two lobes of the stigmas reached $45^{\circ}$. Lethal dose (LD50) was determined using a 1400-Gy dose.

IN VITRO GERMINATION OF IRRADIATION POLLEN. The germination rate of the pollen used was evaluated on a medium containing $2 \%$ sucrose, $1.0 \mathrm{~mm} \mathrm{CaCl}_{2}$, and $0.16 \mathrm{~mm}$ boric acid solidified with $0.65 \%$ Difco Bacto-agar (Merck, Darmstadt, Germany) at $\mathrm{pH} 5.7$ in petri dishes $(55 \mathrm{~mm})$ at $26^{\circ} \mathrm{C}$ and $100 \%$ relative humidity (Luza and Polito, 1985). Germination was recorded after $24 \mathrm{~h}$. Six replications of $\approx 100$ pollen grains in each plate were observed.

Fruit COllection and in vitro Culture. Immature fruit were collected at 30 and $45 \mathrm{~d}$ after pollination in 2008 and $30 \mathrm{~d}$ after pollination in 2009. The fruit were harvested, washed in $15 \%$ commercial bleach ( $0.75 \%$ sodium hypochlorite solution) for $8 \mathrm{~min}$, and then rinsed twice with sterile distilled water for $5 \mathrm{~min}$. The immature embryos were then excised and cultured on DKW medium (Driver and Kuniyuki, 1984) supplemented with $30 \mathrm{~g} \cdot \mathrm{L}^{-1}$ sucrose and $1 \mathrm{mg} \cdot \mathrm{L}^{-1} \mathrm{GA}_{3}$ (Ollitrault et al., 1996). The cultured embryos were kept at $4{ }^{\circ} \mathrm{C}$ for $30 \mathrm{~d}$ before transfer to a growth chamber at $26^{\circ} \mathrm{C}$ and 16-h photoperiod for embryo germination and plant regeneration.

Chromosome number determination. Chromosome number was counted in root tip cells obtained from in vitro-grown haploid and diploid plantlets using the standard Feulgen technique (Lillie, 1951). The root samples were pre-treated with $0.002 \mathrm{M}$ hydroxyquinoline for $8 \mathrm{~h}(4 \mathrm{~h}$ at room temperature and then $4 \mathrm{~h}$ at $4{ }^{\circ} \mathrm{C}$ ). The samples were fixed for $24 \mathrm{~h}$ in 3:1 ethanol:acetic acid and then stored in $70 \%$ ethanol at $4{ }^{\circ} \mathrm{C}$ until viewing. Fixed root tips were placed in aceto-ironhematoxylin dye for staining chromosomes ( $\mathrm{Lu}$ and Raju, 1970). The fixed root tips were hydrolyzed in $1 \mathrm{~N} \mathrm{HCl}$ for 12 min at $60{ }^{\circ} \mathrm{C}$ and squashed in a drop of $45 \%$ (v/v) acetic acid.

Flow CytOMETER analysis. Flow cytometry was used for determination of the ploidy level of samples prepared from leaves of the haploid and diploid (control) in vitro plants. Nuclei were released from $0.5 \mathrm{~cm}^{2}$ of leaf tissue by chopping with a razor blade for $25 \mathrm{~s}$ in $500 \mu \mathrm{L}$ of modified Galbrith's nuclei isolation buffer (Galbrith et al., 1983) containing $200 \mathrm{~mm}$ Tris, $4 \mathrm{~mm} \mathrm{MgCl}_{2} .6 \mathrm{H}_{2} \mathrm{O}$, pH 7.5, 0.5\% Triton X-100 (Partec, Munster, Germany). Then, $500 \mu \mathrm{L}$ of staining solution 4,6diamino-2-phenylindole was added for DNA staining. After 2 min incubation, nuclei were passed through a $30-\mu \mathrm{m}$ nylon filter to eliminate cell debris. The samples were analyzed using a flow cytometer (PA-I; Partec).

MoleCUlar CHARACTERIZATION. SSR markers (microsatellites) were used to characterize maternal origin of the obtained plantlet (Woeste et al., 2002). Genomic DNA was extracted from fresh leaves according to the method of Doyle and Doyle (1987) with minor modifications. Polymerase chain reaction amplifications was carried out in $20 \mu \mathrm{L}$ reaction solution containing $2 \mu \mathrm{L} 10 \times$ buffer $(100 \mathrm{~mm}$ Tris- $\mathrm{HCl}, \mathrm{pH} 8.0,500$ $\mathrm{mm} \mathrm{KCl}), 2 \mathrm{~mm} \mathrm{MgCl} 2,0.2 \mathrm{~mm}$ of each dNDP, and $0.125 \mathrm{~mm}$ of each primer (forward and reverse) of the WGA4, WGA89, WGA118, and WGA321 SSR markers (Woeste et al., 2002). For one unit of Taq polymerase and $60 \mathrm{ng}$ template DNA, the thermal cycling conditions were as follows: an initial denaturation step at $94{ }^{\circ} \mathrm{C}$ for $5 \mathrm{~min}$ followed by 35 cycles at $94{ }^{\circ} \mathrm{C}$ for $45 \mathrm{~s}$, an annealing step at $75{ }^{\circ} \mathrm{C}$ for $40 \mathrm{~s}$, and an extraction at $72{ }^{\circ} \mathrm{C}$ for 1 min with a final extraction step at $72{ }^{\circ} \mathrm{C}$ for $10 \mathrm{~min}$; the product was run on a $1-\mathrm{mm}$-thick, $6 \%$ nondenaturing polyacrylamide gel. Gels were pre-run at $1500 \mathrm{~V}$ for $30 \mathrm{~min}$, and the samples were loaded and run at $1500 \mathrm{~V}$ for $\approx 1 \mathrm{~h}$. Fragments were visualized by silver staining (Bassam et al., 1991). Each gel had a 100- to 1000-bp DNA ladder and a standard sample to estimate molecular weight and to control gel-to-gel variation.

\section{Results}

IN VITRO VIABILITY OF IRRADIATED POLLEN. In vitro germination of irradiated pollen was determined for both male parents. Irradiation by low doses ( 0 to $150 \mathrm{~Gy}$ ) of gamma rays had little effect on pollen germination. The germination rate of control

Table 1. Mean in vitro germination percentage of gamma-irradiated pollen grains of two persian walnut genotypes in 2008 .

\begin{tabular}{ccc}
\hline & \multicolumn{2}{c}{ Germination rate $(\%)$} \\
\cline { 2 - 3 } Irradiation dose (Gy) & $\mathrm{Z}_{30}$ & $\mathrm{Z}_{53}$ \\
\hline 0 & $76.20 \mathrm{a}^{\mathrm{z}}$ & $76.00 \mathrm{a}$ \\
50 & $75.38 \mathrm{a}$ & $75.58 \mathrm{a}$ \\
150 & $72.30 \mathrm{~b}$ & $72.70 \mathrm{~b}$ \\
300 & $71.06 \mathrm{bc}$ & $69.66 \mathrm{c}$ \\
600 & $69.50 \mathrm{c}$ & $67.20 \mathrm{~d}$
\end{tabular}

zPercentages followed by the same letters are not significantly different at the $5 \%$ level by Newman and Keuls test.

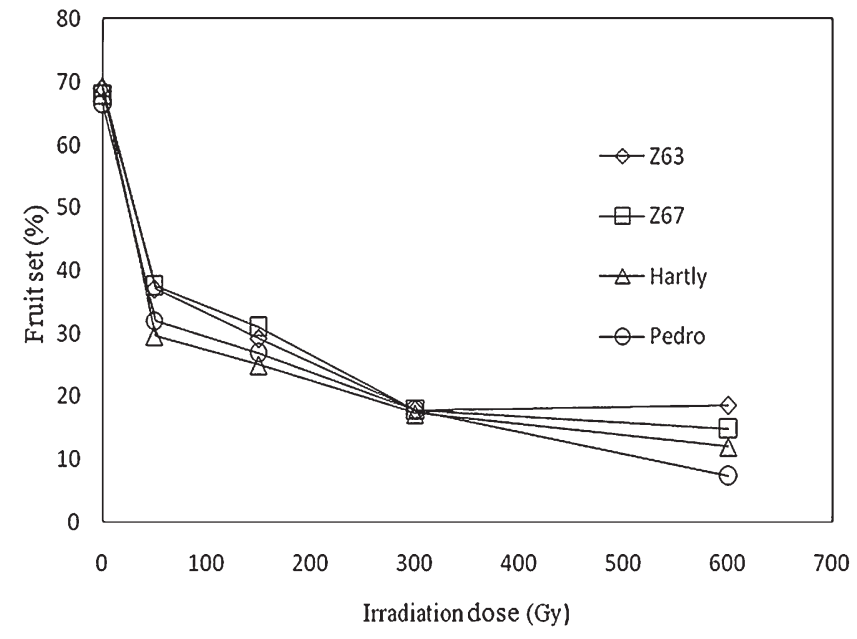

Fig. 1. Effect of pollen gamma-irradiation dose on percentage of fruit set $30 \mathrm{~d}$ after pollination using pollen of selection $Z_{30}$ (2008) on four female genotypes of persian walnut. 
pollen was $\approx 76 \%$ compared with $75 \%$ for $50-$ Gy- and $71 \%$ for 300-Gy-treated pollen. At higher irradiation doses (600 and 900 Gy), the germination capacity was significantly reduced $(\approx 67 \%$ at $600 \mathrm{~Gy}$ ) (Table 1). LD ${ }_{50}$ determined using the 1400-Gy dose and $39.6 \%$ germination was observed.

EFFECT OF POLLINATION ON FRUIT SET AND EMBRYO DEVELOPMENT. For all cross combinations in 2008 and 2009, pollen irradiated at doses ranging from 50 to 900 Gy significantly reduced fruit set, in particular for 'Pedro', compared with the control and pollen irradiated at 50 and 150 Gy (Fig. 1). The degree to which irradiated pollen affected fruit set was dependent on genotype and irradiation dose. The size of fruit set using control pollen or pollen irradiated with lower doses (50 or $150 \mathrm{~Gy}$ ) was obviously larger than fruit set using pollen treated with the highest dose (600 Gy). Use of irradiated pollen led to
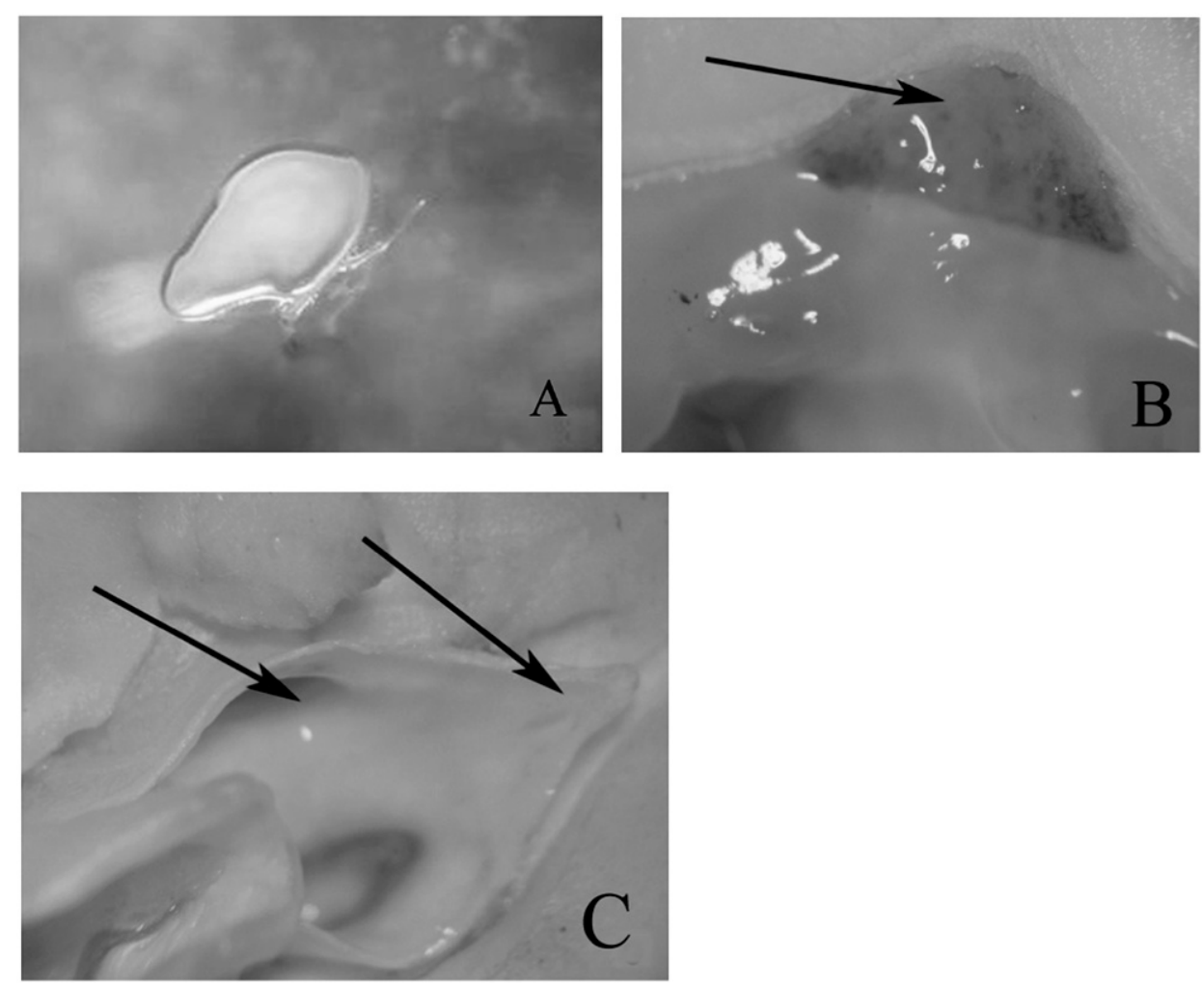

Fig. 2. Effect of gamma irradiation of pollen on fruit content $45 \mathrm{~d}$ after pollination of genotype $Z_{63}$ of persian walnut. (A) Parthenogenetic embryo resulting from pollen treated with a 300-Gy dose. (B) Fruit containing only endosperm, obtained using 600-Gy-treated pollen, arrow shows location where embryo would be expected to develop. (C) Result using 600-Gy-treated pollen; arrows show locations of endosperm and expected embryo development in normal fruit. the formation of parthenocarpic fruit in all female parents. With increasing irradiation doses, the tendency to produce parthenocarpic fruit increased but the percentage of empty fruit and fruit containing embryos without endosperm increased (Fig. 2). This tendency was intensified in all four female genotypes when pollen irradiation doses exceeded 300 Gy (Fig. 2). All the fruit of control pollen contained normal embryo and endosperm. However, $\mathrm{Z}_{63}, \mathrm{Z}_{67}$, 'Hartley', and 'Pedro' had only $57 \%, 50 \%$, $40 \%$, and $35.7 \%$, respectively, of fruit with endosperm and embryos when pollinated with irradiated pollen of $\mathrm{Z}_{30}$; and only $58.8 \%, 40 \%, 44.4 \%$, and $50 \%$, respectively, had endosperm and embryos when pollinated with irradiated pollen of $Z_{53}$. The same result was obtained for $Z_{30}$ in 2009 (data not shown).

Embryo formation. The embryo (diploid and haploid) production of female parents was dependent on the genotype and dose of gamma irradiation. Embryos were produced in all treatments (pollen irradiation doses $\times$ genotypes) except the 'Pedro' at the 900-Gy treatment in which no embryo was found. For all female parents, when pollen irradiation doses were higher than $300 \mathrm{~Gy}$, the number of embryos was clearly reduced (Table 2).

INFLUENCE OF FRUIT-COLLECTING STAGES. In 2008, fruit for in vitro culture of immature embryos were collected 30 and $45 \mathrm{~d}$ after pollination. At $45 \mathrm{~d}$ after pollination, only fruit of $Z_{67}$ were harvested from the 600-Gy dose treatments and five fruit were harvested among all the female plants from crosses using the $300-G y$ dose. The rate of fruit abscission $45 \mathrm{~d}$ after pollination was lower for the 50- and 150-Gy doses than for the 300- and 600-Gy treatments. There was no difference in embryo germination rates between fruit harvested 30 and $45 \mathrm{~d}$ after pollination.

Ploidy level. Haploid status was determined by chromosome counting and flow cytometry (Figs. 3 and 4). Sixteen chromosomes were visible in haploids. All the plants produced from pollination

Table 2. Effect of gamma-irradiated pollen of persian walnut genotypes $Z_{30}$ and $Z_{53}$ on embryo production of four persian walnut genotypes used as female parents in 2008 and 2009.

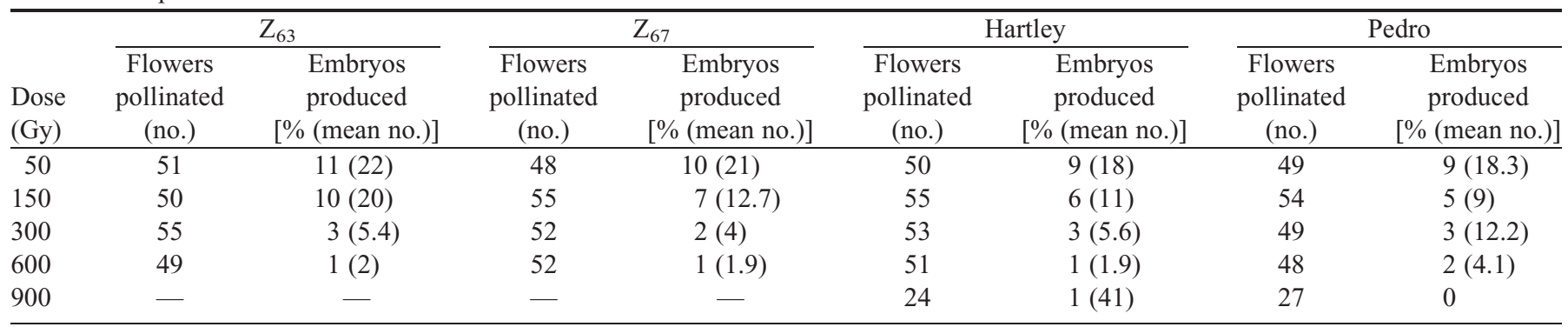




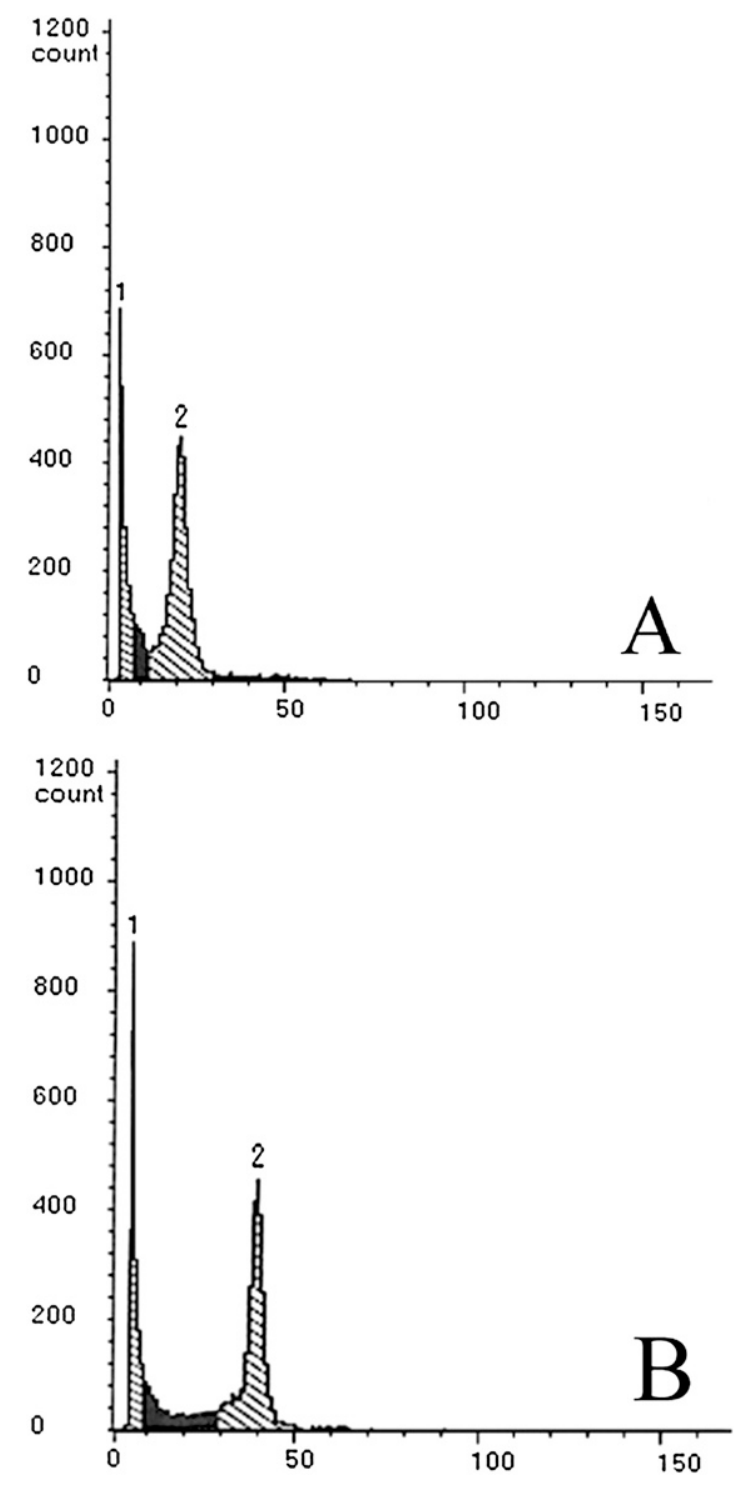

Fig. 3. Flow cytometry of diploid and haploid plants of persian walnut; 4,6diamidino-2-phenylindole (DAPI) fluorescence of nuclei (x-axis) versus number of nuclei counted (y-axis) in haploid (A) and diploid (B) plants of 'Hartley'.

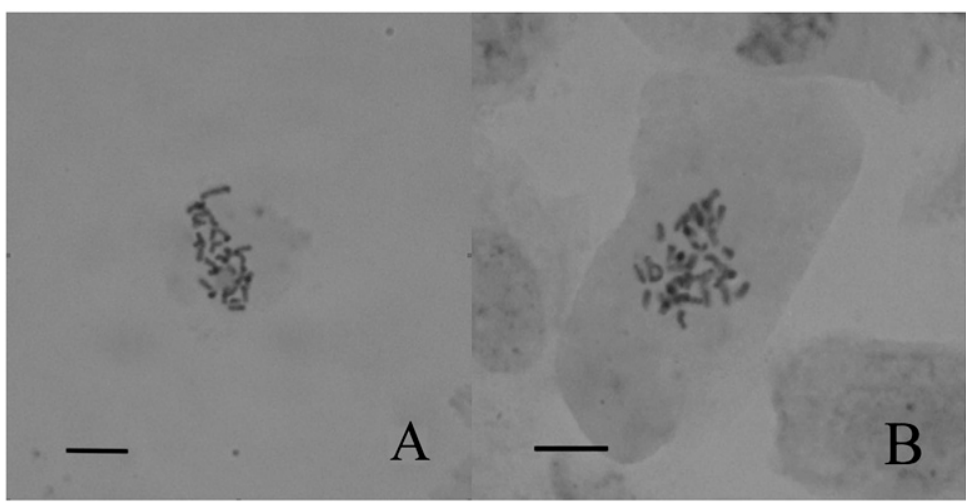

Fig. 4. (A) Haploid cell $(2 \mathrm{n}=\mathrm{x}=16)$ observed in a root apex of an embryo collected from $\mathrm{Z}_{63}$ genotype of persian walnut. (B) Diploid cell $(2 n=2 x=32)$ observed in a root apex of an embryo collected from $Z_{63}$ persian walnut genotypes. (C) Chromosome numbering in a haploid embryo from $Z_{63}$ persian walnut genotype using MicroMeasure software (Version 3.3; Colorado State University, Fort Collins, CO) clearly showing the 16 chromosomes; bar $=10 \mu \mathrm{m}$.

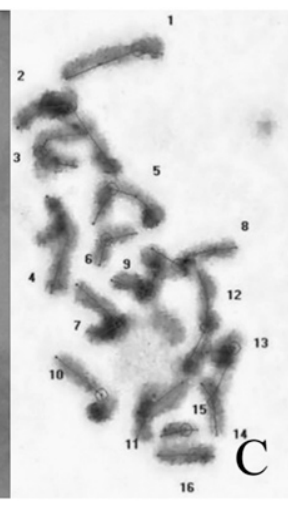

by non-irradiated pollen or the 50- and 150-Gy-irradiated treatments were diploid. Haploid plantlets were obtained only when 300 and 600 Gy of irradiation was used. $Z_{63}$ and $Z_{67}$ female parents produced haploid plants from 600-Gy-treated pollen of both $Z_{53}$ and $Z_{30}$. Two haploid plants were obtained from 'Pedro' pollinated with $300-$ Gy-treated pollen of $Z_{30}$ (one in 2008 and another in 2009). One haploid plant was obtained from 'Hartley' using 600-Gy-treated pollen of $Z_{30}$ in 2009. No plants were recovered from the 900-Gy treatment used in 2009. In total, 64 plants were evaluated for ploidy level, of which 59 plants $(92.18 \%)$ were diploid and five plants $(7.81 \%)$ were haploid (Table 3). The haploid plants had smaller leaves and weak vigor in comparison with diploids (Fig. 5).

Molecular analysis. The genetic origin of all plantlets was analyzed with four SSR markers (Table 4). Banding patterns (fingerprinting) obtained for each plantlet were compared with their parents. Using four markers, the five haploid plantlets presented only one allele of their female parents. None of the specific alleles of $Z_{30}$ and $Z_{53}$ were observed. For example, a haploid 'Pedro' and $Z_{63}$ presented only one specific maternal allele (224 bp) for the locus WGA321 (Fig. 6A), and a haploid 'Hartley' and $\mathrm{Z}_{67}$ presented only one band at 212 and $222 \mathrm{bp}$, respectively, for the locus WGA89 [Fig. 6B (Lanes 4 and 3, respectively)]. These profiles confirmed the parthenogenetic origin of the obtained haploid plants. All diploid plantlets presented a heterozygous profile with one female allele and one male allele. For example, WGA321 was heterozygous in diploid plants. Number 1 ('Pedro') showed a band at $244 \mathrm{bp}$ and presented a second different band from $Z_{53}$ at $236 \mathrm{bp}$. Number $2\left(Z_{63}\right)$ with one band at $224 \mathrm{bp}$ presented a second band different from $Z_{53}$ at $248 \mathrm{bp}$ (Fig. 6A). These profiles are those of zygotic with $Z_{30}$ and $Z_{53}$. Therefore, we did not obtain any diploid plantlets originated from $2 \mathrm{n}$ female or double haploids.

\section{Discussion}

Comparison of the germination rate for pollen irradiated at 900 Gy $(64 \%)$ and 1400 Gy (39.6\%) to non-irradiated pollen (76\%) indicates that irradiation with more than 900 Gy has a significant effect on pollen viability (Table 1). It also implies that persian walnut, in particular $Z_{53}$, is more sensitive to ionizing radiation than other fruit trees such as sweet cherry and apple (Höfer and Grafe, 2003; Zhang and Lespinasse, 1991). Gamma irradiation at 900 Gy had no significant effect on pollen germination in mandarin (Froelicher et al., 2007). Bouvier et al. (1993) observed only small differences in germination between pear pollen irradiated up to 500 Gy and non-irradiated control pollen. Our results are similar and consistent with those published by Peixe et al. (2000) for european plum (Prunus domestica cv. Rainha Claudia Verde), by Rode and Dumas de Vaulx (1987) for carrot (Daucus carota), and by AduAmmphomah et al. (1991) for cacao (Theobroma cacao) in which all 
Table 3. Effect of gamma-irradiated pollen on embryo and parthenogenetic plant production of persian walnut cultivars and genotypes in 2008 and 2009.

\begin{tabular}{|c|c|c|c|c|}
\hline $\begin{array}{l}\text { Female } \\
\text { parent }\end{array}$ & $\begin{array}{c}\text { Irradiation } \\
\text { dose (Gy) }\end{array}$ & $\begin{array}{c}\text { Embryos } \\
\text { obtained }(\%)\end{array}$ & $\begin{array}{l}\text { Haploids } \\
\text { (no.) }\end{array}$ & $\begin{array}{c}\text { Diploids } \\
\text { (no.) }\end{array}$ \\
\hline \multirow[t]{5}{*}{$\overline{Z_{63}}$} & 50 & 11 & 0 & 8 \\
\hline & 150 & 10 & 0 & 7 \\
\hline & 300 & 3 & 0 & 1 \\
\hline & 600 & 1 & 1 & 1 \\
\hline & 900 & - & - & - \\
\hline \multirow[t]{5}{*}{$Z_{67}$} & 50 & 10 & 0 & 8 \\
\hline & 150 & 7 & 0 & 7 \\
\hline & 300 & 2 & 0 & 1 \\
\hline & 600 & 1 & 1 & 0 \\
\hline & 900 & - & - & - \\
\hline \multirow[t]{5}{*}{ Hartley } & 50 & 9 & 0 & 6 \\
\hline & 150 & 6 & 0 & 5 \\
\hline & 300 & 3 & 0 & 4 \\
\hline & 600 & 1 & 1 & 0 \\
\hline & 900 & 1 & 0 & 0 \\
\hline \multirow[t]{5}{*}{ Pedro } & 50 & 9 & 0 & 6 \\
\hline & 150 & 5 & 0 & 4 \\
\hline & 300 & 3 & 2 & 0 \\
\hline & 600 & 2 & 0 & 1 \\
\hline & 900 & 0 & 0 & 0 \\
\hline Total & & 84 & 5 & 59 \\
\hline
\end{tabular}

irradiation levels tested had a significant effect on pollen viability.

Pollination with irradiated pollen affected fruit set for all female parents tested. These results are in agreement with the observations in melon (Cucumis melo) (Lotfi et al., 2003), european plum (Peixe et al., 2000), cacao (Falque et al., 1992), and apple (Zhang and Lespinasse, 1991) in which all seeds from untreated pollen contained both embryo and endosperm. However, $41.6 \%, 17.7 \%$, and $3 \%$ of seeds from irradiated pollen treatments for 'Erovan', 'Golden Delicious', and 'X6677', respectively, contained only endosperm. In contrast, Chalak and Legave (1997) reported that in kiwifruit, fruit set using control pollen was not significantly different from results using irradiated pollen at $1500 \mathrm{~Gy}$. In apple, James et al. (1985) and Nicoll et al. (1987) also obtained seeds containing only endosperm or endosperm and embryos after pollination with irradiated pollen. Based on these results, they concluded that at high levels of irradiation, only a single sperm nuclei is present in pollen tube, allowing fertilization of either the egg cell or the fused polar nuclei.

An explanation for fruit drop at 30 and $45 \mathrm{~d}$ after use of pollen irradiated at 300 or 600 Gy could be that the pollen tube is not able to reach the ovule, resulting in an early embryo abortion and consequent fruit drop (Peixe et al., 2000). The plants obtained from pollen irradiated at 50 and 150 Gy suggest these are insufficient doses for pollen sterility (Froelicher et al., 2007). According to Sestili and Ficcadenti (1996), low levels of irradiation may damage only part of the generative nucleus while maintaining its capacity to fertilize the egg cell and lead to hybridization.

In this research, the four persian walnut female parents responded positively to in situ parthenogenetic haploid

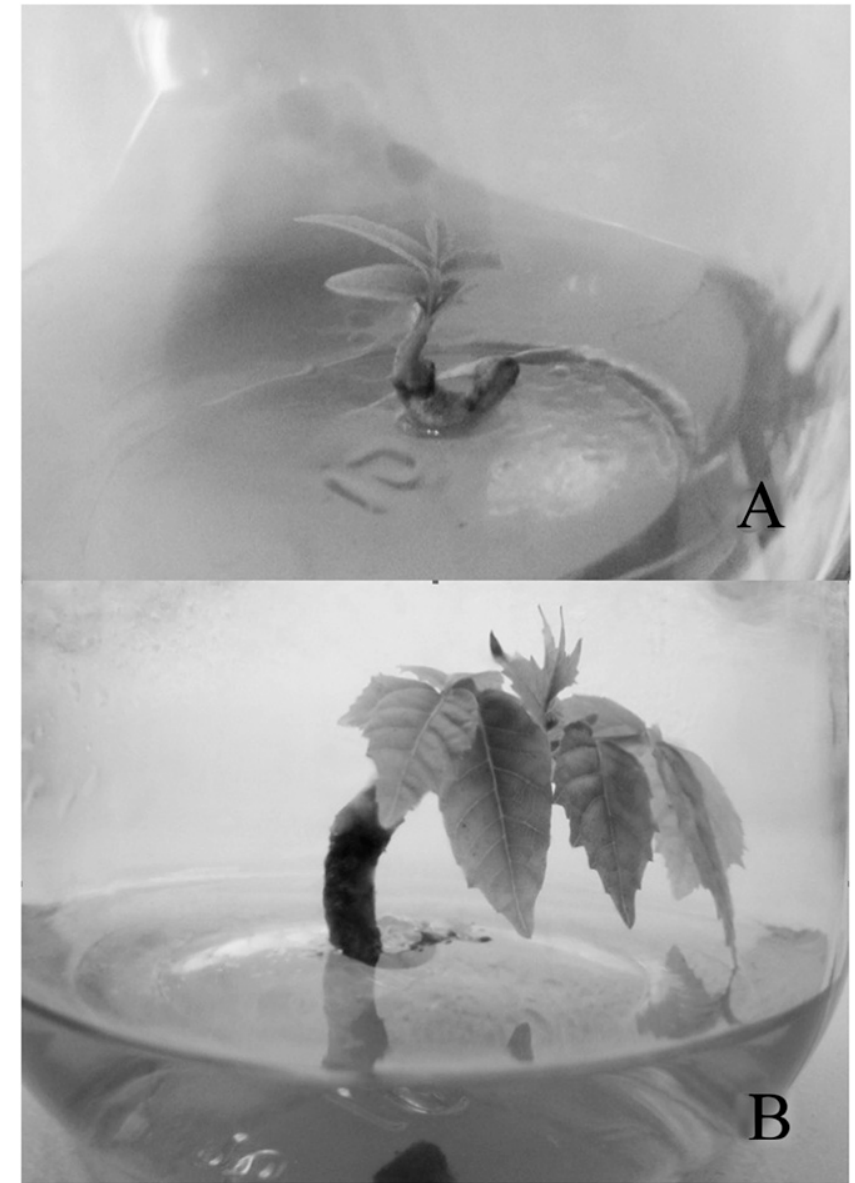

Fig. 5. (A) Haploid plant of persian walnut 'Hartley' obtained using pollen irradiation with 600-Gy dose. (B) Diploid embryo of the same plant.

Table 4. Allelic constitution characterized by their size of the different persian walnut genotypes analyzed using simple sequence repeat markers (Woeste et al., 2002).

\begin{tabular}{lcccccl}
\hline \multicolumn{7}{c}{ Allelic constitution size (bp) } \\
\hline$Z_{53}$ & $Z_{30}$ & $Z_{67}$ & $Z_{63}$ & Pedro & Hartley & Locus \\
\hline $236 / 248$ & $236 / 236$ & $236 / 236$ & $224 / 248$ & $224 / 244$ & $244 / 244$ & WGA321 \\
$216 / 216$ & $212 / 222$ & $218 / 222$ & $216 / 216$ & $216 / 216$ & $212 / 216$ & WGA89 \\
$184 / 196$ & $192 / 192$ & $196 / 196$ & $184 / 199$ & $192 / 199$ & $199 / 199$ & WGA118 \\
$230 / 236$ & $230 / 230$ & $236 / 236$ & $230 / 230$ & $230 / 230$ & $230 / 230$ & WGA4 \\
\hline
\end{tabular}

induction using irradiated pollen followed by in vitro culture of immature embryos. All haploids were obtained by irradiation doses of 300 or $600 \mathrm{~Gy}$. The totals of 59 diploid plants were obtained using pollen treated at four doses $(50,150,300$, and $600 \mathrm{~Gy})$. At $900 \mathrm{~Gy}$, no plants were generated. The best dose for haploid production in persian walnut was 300 or $600 \mathrm{~Gy}$. In comparison, 300 Gy gave the best results for mandarin (Froelicher et al., 2007), and 200 or 500 Gy was the best for apple (Zhang and Lespinasse, 1991).

Molecular marker analysis showed that all the diploid plants recovered were zygotic and no spontaneous double haploid plants were obtained in this work, whereas in melon (Lotfi et al., 2003), spontaneous double haploids were generated by induced parthenogenesis. Our results are in agreement with observations in apple (Zhang and Lespinasse, 1991), mandarin (Froelicher et al., 2007), and european plum (Peixe et al., 2000). Future 


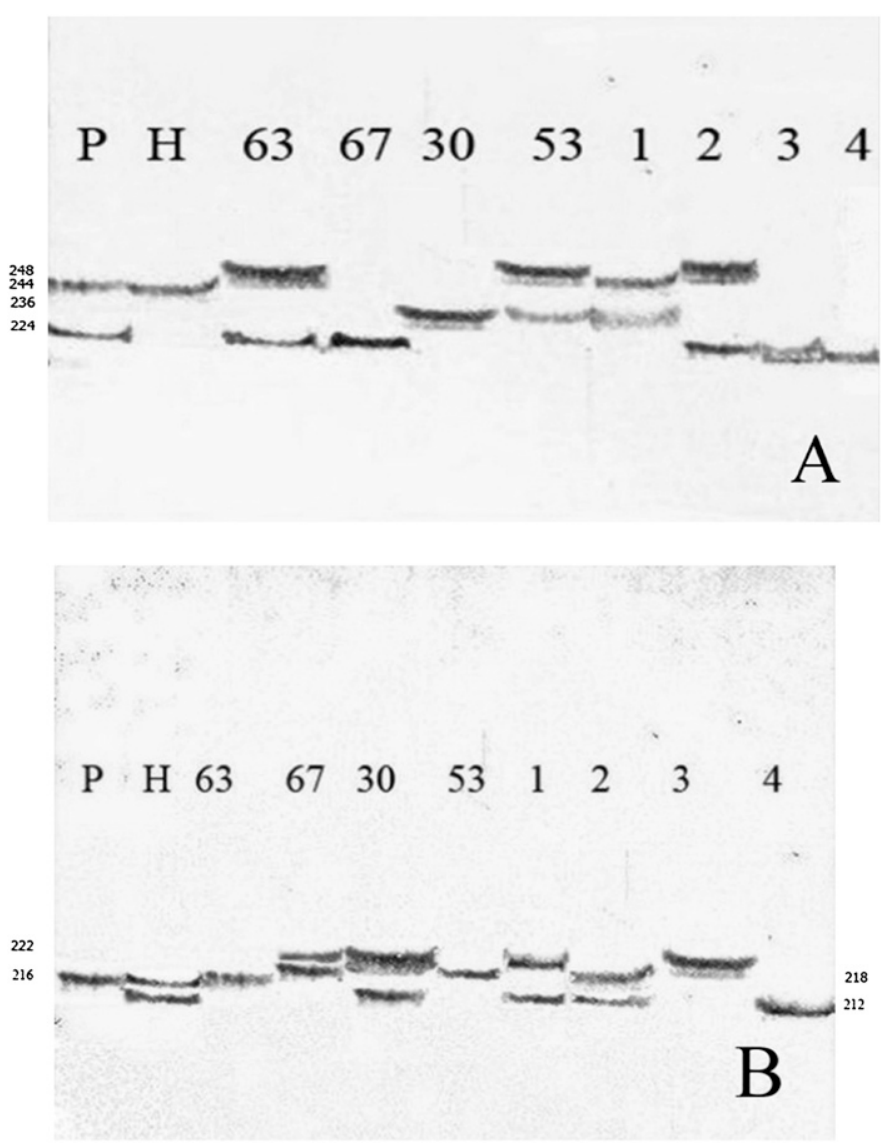

Fig. 6. Polyacrylamide gels showing the constitution of recovered plantlets of persian walnut analyzed by simple sequence repeat (SSR) markers: (A) SSR marker WGA321; (B) SSR marker WGA 89. For both gels: $\mathrm{P}=$ 'Pedro'; $\mathrm{H}=$ 'Hartley'; $63=\mathrm{Z}_{63} ; 67=\mathrm{Z}_{67} ; 30=\mathrm{Z}_{30} ; 53=\mathrm{Z}_{53}$. For gel $(\mathbf{A}): 1=$ diploid 'Pedro'; $2=\operatorname{diploid} Z_{63} ; 3=$ haploid 'Pedro'; and $4=$ haploid $Z_{63}$. For gel (B): $1=\operatorname{diploid}$ $\mathrm{Z}_{67} ; 2=$ diploid 'Hartley'; $3=$ haploid $\mathrm{Z}_{67}$; and $4=$ haploid 'Hartley'.

experiments could test 400, 500, and 750 Gy to determine the capacity of these treatments to produce more haploids with fewer diploids and reduced fruit drop.

\section{Conclusion}

This study shows the optimum conditions for inducing in situ parthenogenesis in persian walnut include: 1) use of pollen irradiated at 300 or $600 \mathrm{~Gy}$; 2) collection of fruit $30 \mathrm{~d}$ after pollination; and 3) cold treatment of embryos at $4{ }^{\circ} \mathrm{C}$ for $30 \mathrm{~d}$. However, it remains to be determined 1) the origin of haploid and diploid embryos; and 2) the mechanism of parthenogenetic development induced by gamma-irradiated pollen. At present, the homozygous lines obtained from this study are in the in vitro propagation stage and will be grafted and acclimatized for further studies. The haploid plants have potential importance for progress in genomics and contribution to breeding of persian walnut in which the genome size is approximately three times the size of the human genome.

\section{Literature Cited}

Adu-Ammphomah, H., J. Novak, G.Y.P. Klu, and T.V.O. Lamptey. 1991. Use of irradiated pollen as mentor pollen to induce selffertilization of two self-incompatible upper amazon cacao clones. Euphytica 51:219-225.
Bassam, B.J., G. Caetano-Anolles, and P.M. Gresshoff. 1991. Fast and sensitive silver staining of DNA in polyacrylamide gels. Anal. Biochem. 196:80-83.

Bouvier, L., Y.X. Zhang, and Y. Lespinasse. 1993. Two methods of haploidization in pear, Pyrus communis L.: Greenhouse seedling selection and in situ parthenogenesis induced by irradiated pollen. Theor. Appl. Genet. 87:229-232.

Chalak, L. and J.M. Legave. 1997. Effects of pollination by irradiated pollen in Hayward kiwifruit and spontaneous doubling of induced parthenogenetic trihaploids. Sci. Hort. 68:83-93.

Doyle, J. and J. Doyle. 1987. A rapid DNA isolation procedure for small quantities of fresh leaf tissue. Phytochem. Bul. 19:11-15.

Driver, J.A. and A.H. Kuniyuki. 1984. In vitro propagation of Paradox walnut rootstock. HortScience 19:507-509.

Falque, M., A.A. Kodia, O. Sounigo, A.B. Eskes, and A. Charrier. 1992. Gamma irradiation of cacao (Theobroma cacao) pollen: Effect on pollen grain viability, germination and mitosis and on fruit set. Euphytica 64:167-172.

Froelicher, Y., J.B. Bassene, E. Jadidi-Neji, D. Dambier, R. Morillon, G. Bernardini, G. Costantino, and P. Ollitrault. 2007. Induced parthenogenesis in mandarin for haploid production: Induction procedures and genetic analysis of plantlets. Plant Cell Rep. 26: 937-944.

Galbrith, D.W., K.R. Harkins, J.M. Maddox, N.M. Ayres, D.P. Sharma, and E. Firoozabady. 1983. Rapid flow cytometric analysis of the cell cycle in intact plant tissues. Science 220:1049-1051.

Germana, M.A. 2006. Double haploid production in fruit trees. Plant Cell Tissue Organ Cult. 86:131-146.

Germana, M.A. 2009. Haploids and doubled haploids in fruit trees, p. 241-263. In: Jain, S.M., S.K. Sopory, and R.E. Veilleux (eds.). Advances in haploid production in higher plants. Springer, Berlin, Germany.

Höfer, M. and C.H. Grafe. 2003. Induction of doubled haploids in sweet cherry (Prunus avium). Euphytica 130:191-197.

Höfer, M. and Y. Lespinasse. 1996. Haploidy in apple, p. 259-274. In: Jain, S.M., S.K. Sopory, and R.E. Veilleux (eds.). In vitro haploid production in higher plants. 3rd Ed. Kluwer, Dordrecht, The Netherlands.

James, D.J., A.J. Passey, K.A.D. Mackenzie, and E.C. Menhinick. 1985. The effects of pollen irradiation on the development of the post-fertilization ovule of apple (Malus pumila), p. 210-224. In: Chapman, G.P.C., S. Mantell, and R. Daniels (eds.). Experimental manipulation of ovule tissues. Longman, London, UK.

Khush, G.S. and S.S. Virmani. 1996. Haploids in plant breeding, p. 11-33. In: Jain, S.M., S.K. Sopory, and R.E. Veilleux (eds.). In vitro haploid production in higher plants. 3rd Ed. Kluwer, Dordrecht, The Netherlands.

Lillie, R.D. 1951. Simplification of the manufacture of Schiff reagent for use in histochemical procedures. Stain Technol. 26:163-165.

Lotf, M., A.R. Alan, M.J. Henning, and M.M. Jahn. 2003. Production of haploid and doubled haploid plants of melon (Cucumis melo) for use in breeding for multiple virus resistance. Plant Cell Rep. 21: $1121-1128$.

Lu, B.C. and N.B. Raju. 1970. Meiosis in Coprinus. II. Chromosome pairing and the lampbrush diplotene stage of meiotic prophase. Chromosoma 29:305-316.

Luza, J.M. and V.S. Polito. 1985. Progamy and chalazogamy in walnut (Juglans regia). Bot. Gaz. 152:100-106.

Nicoll, M.F., G.P. Chapman, and D.J. James. 1987. Endosperm responses to irradiated pollen in apples. Theor. Appl. Genet. 74: 508-515.

Ollitrault, P., V. Allent, and F. Luro. 1996. Production of haploid plants and embryogenic calli of clementine (Citrus reticulata) after in situ parthenogenesis induced by irradiated pollen. Proc. Intl. Soc. Citriculture South Africa 2:913-917.

Pandey, K.K., L. Przywara, and P.M. Sanders. 1990. Induced parthenogenesis in kiwifruit (Actinidia deliciosa) through the use of lethally irradiated pollen. Euphytica 51:1-9. 
Peixe, A., M.D. Campos, C. Cavaleiro, J. Barroso, and M.S. Pais. 2000. Gamma-irradiated pollen induces the formation of $2 \mathrm{n}$ endosperm and abnormal embryo development in european plum (Prunus domestica cv. Rainha Clàudia Verde). Sci. Hort. 86:267-278.

Rode, J.C. and R. Dumas de Vaulx. 1987. Obtention de plantes haploides de carotte (Daucus carota) issues de parthénogenése induite in situ par du pollen irradié et culture in vitro de graines immatures. Comptes Rendus de l'Académie des Sciences Paris 305:225-229.
Sestili, S. and N. Ficcadenti. 1996. Irradiated pollen for haploid production, p. 263-247. In: Jain, S.M., S.K. Sopory, and R.E. Veilleux (eds.). In vitro haploid production in higher plants. 3rd Ed. Kluwer, Dordrecht, The Netherlands.

Woeste, K., R. Burns, O. Rhodes, and C. Michler. 2002. Thirty polymorphic nuclear microsatellite loci from black walnut. J. Hered. 93:58-60.

Zhang, Y.X. and Y. Lespinasse. 1991. Pollination with gammairradiated pollen and development of fruits, seeds and parthenogenetic plant in apple. Euphytica 54:101-109. 